\title{
A Systematic Methodology for Comprehensive Economic Assessment of Process Control Structures
}

A. Udugama, Isuru; Taube, Michael A.; Mansouri, Seyed Soheil; Kirkpatrick, Robert; Gernaey, Krist V.; Yu, Wei; Young, Brent R.

Published in:

Industrial and Engineering Chemistry Research

Link to article, DOI:

10.1021/acs.iecr.8b01883

Publication date:

2018

Document Version

Peer reviewed version

Link back to DTU Orbit

Citation (APA):

A. Udugama, I., Taube, M. A., Mansouri, S. S., Kirkpatrick, R., Gernaey, K. V., Yu, W., \& Young, B. R. (2018). A Systematic Methodology for Comprehensive Economic Assessment of Process Control Structures. Industrial and Engineering Chemistry Research, 57(39), 13116-13130. https://doi.org/10.1021/acs.iecr.8b01883

\section{General rights}

Copyright and moral rights for the publications made accessible in the public portal are retained by the authors and/or other copyright owners and it is a condition of accessing publications that users recognise and abide by the legal requirements associated with these rights.

- Users may download and print one copy of any publication from the public portal for the purpose of private study or research.

- You may not further distribute the material or use it for any profit-making activity or commercial gain

- You may freely distribute the URL identifying the publication in the public portal 


\section{A Systematic Methodology for Comprehensive}

\section{Economic Assessment of Process Control Structures}

Isuru A. Udugama ${ }^{1, * *}$, Michael A. Taube ${ }^{2}$, Seyed Soheil Mansouri ${ }^{3}$, Robert Kirkpatrick ${ }^{1}$, Krist V. Gernaey ${ }^{3}$, Wei $\mathrm{Yu}^{1}$, Brent R. Young ${ }^{1, *}$

${ }^{1}$ Department of Chemical \& Materials Engineering, the University of Auckland, Auckland, New Zealand

${ }^{2} \mathrm{~S} \&$ D Consulting LLC, Houston, Texas, U.S.A

${ }^{3}$ Process and Systems Engineering Center (PROSYS), Department of Chemical and Biochemical Engineering, Technical University of Denmark, Lyngby, Denmark

*Correspondence: b.young@auckland.ac.nz

KEYWORDS Economic analysis, Systematic assessment, Techno-economic analysis, Process control

** Current Affiliation: Process and Systems Engineering Center (PROSYS), Department of Chemical and Biochemical Engineering, Technical University of Denmark, Lyngby, Denmark 


\section{ABSTRACT}

The efficient operation of many modern industrial unit operations is a fine balancing act between the need to operate as close as possible to the optimal operating conditions, while still having sufficient ability to overcome non-routine process upsets. The need to balance these opposing requirements is most evident when assessing new process control structures for existing unit operations. While there are control performance analysis techniques and assessment methodologies available to assess control structures, these techniques and methodologies do not explicitly calculate the overall economic impact and are also complicated to use. In this manuscript, a novel, versatile methodology is proposed to systematically analyse the expected economic benefits of process control structures taking into consideration their overall impact on plant operations. It is a hierarchical systematic methodology that will identify opportunities to improve economic operations, identify relevant process control structures and finally comprehensively quantify the overall economic benefits of implementing a new control structure versus current operations. This methodological approach employs Net Present Value (NPV) to systematically assess the economic implications while employing process safety/risk analysis concepts developed in the Layer of Protection Analysis (LOPA) to translate process upset information and subsequent control actions into economic consequences that are then used in the NPV analysis. The methodology is then applied to a case study of a high purity methanol distillation unit located in an industrial methanol production plant, where two new process control alternatives were compared against the current operations. Through the case study, it is 
illustrated how the comprehensive economic information generated by the proposed method can aid an informed decision-making process.

\section{INTRODUCTION}

Introduction of new process control structures/operations in the process industry can be a complicated process, as different parties (mainly plant operations and process engineers) have varying opinions about what constitutes economically optimal operations. For example, in distillation operations, process engineers will favour operating the unit close to product purity limits at high product recovery rates using the lowest reboiler duty. This type of improved economic operation is typically achieved by the introduction of well-designed process control structures that can operate the column well during routine process upsets. However, for plant operators, this type of improved process control is risky, as there is a minimal process buffer to counter unexpected process disturbances. As such, the decision to implement a new process control structure, which at first glance seems trivial, can be complicated by these opposing ideologies. Currently, such implementation decisions are taken by senior engineers and managers of industrial plants based on their experience and judgement.

The need to understand the economics of process control has been a topic of interest for decades both in academia and industry. For example, in the 1960 's, Williams ${ }^{1}$ focused on calculating the costs and benefits of fitting new "digital devices" to replace the then industry standard pneumatic and analogue controls. Since these early days, the field of controller performance assessment (CPA) has grown significantly with multiple established techniques, methodologies and mathematical formulae designed to quantify the benefits brought by process control ${ }^{2}$. Most of 
the techniques developed have focused their analysis on single, linear control loops ${ }^{2}$ while in more recent times CPA methods have been extended to be applicable for single non-linear control loops through the use of methods such as time series analysis ${ }^{3,4}$. The concept of CPA is also becoming important in non-chemical processes such as bio-based production, where there is a growing body of work on controlling key economically critical process variables ${ }^{5}$. In general, most CPA assessment methodologies focus on the analysis of single-input-single-output (SISO) control loops and focus on producing a technical metric. However, some CPA frameworks and studies have analysed the economics of SISO controls ${ }^{6-8}$. For example, a long-term, comprehensive investigation on how to quantify the economic benefits of process control on the overall plant performance was conducted by the Warren Centre in Australia ${ }^{7}$. The study discusses methods to analyse the benefits of new/modified controllers and considers the influence of disturbances on control systems and the role of control systems in achieving better plant performance ${ }^{7,9}$, whilst another study proposed a methodology to quantify the economic costs that disturbances and model uncertainty have on process control ${ }^{10}$.

With respect to the economic assessment of advanced process control (APC) applications, such as adaptive or model predictive control, there are little to no established systematic methodologies that are currently in use ${ }^{11}$. As a result, most APC suppliers and users applied an economic benefits analysis based on experience and simplicity rather than on objectives ${ }^{11}$. The author's industrial experience also confirms this finding where many APC implementers use their considerable experience in implementation to "estimate" the benefits. However, many implementers fail to account for the on-going maintenance (particularly staff costs). Thus, over time, benefits degrade, often rapidly, usually from a "lack of support". Bauer and Craig ${ }^{11}$ have discussed a methodological approach that can help with this decision-making process. However, 
this proposed framework by Bauer and Craig is mainly a guideline for what factors should be considered. In Figure 1, a timeline of the key developments in domain of economic assessment of process control loops and structures is presented together with the key developments proposed in this manuscript.

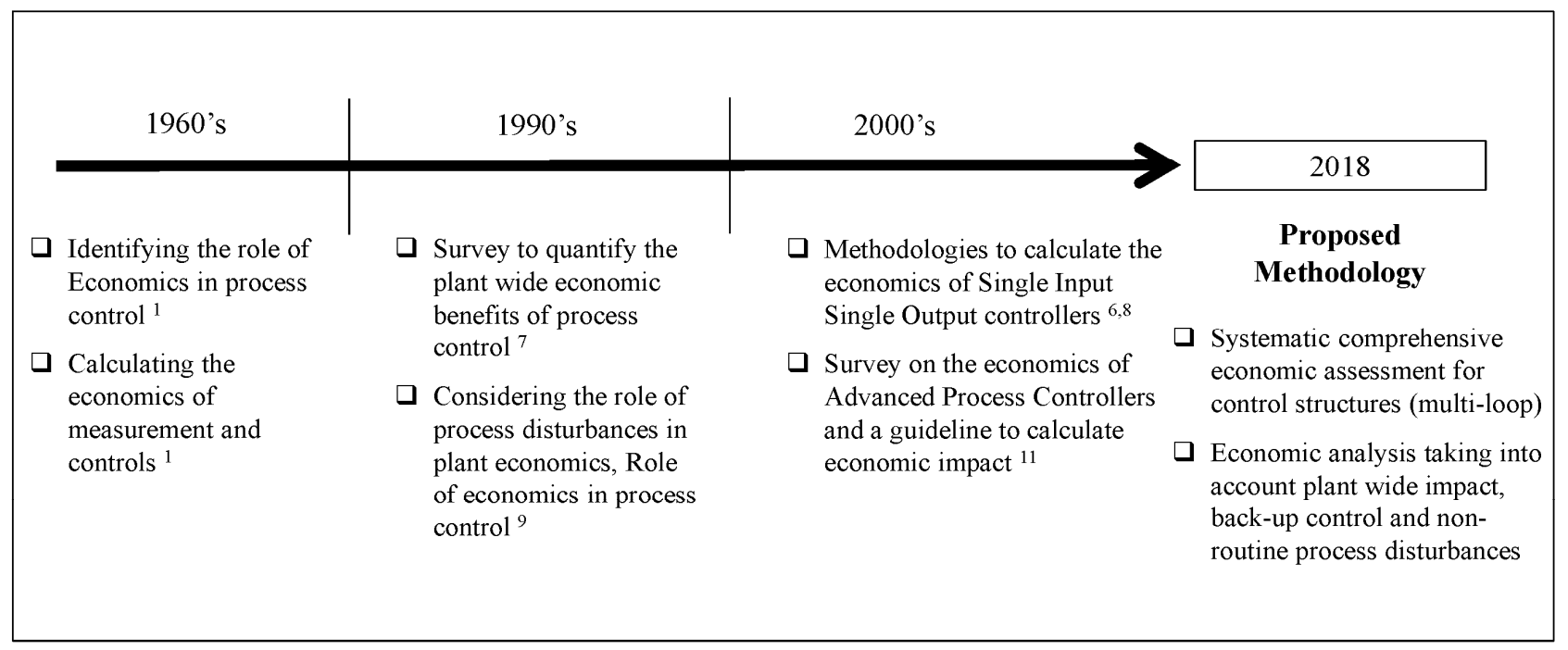

Figure 1: Key development in the domain of economics related to CPA in the last 60 years

Figure 1 illustrates the relevance of economics in the domain of CPA in general as well as in control structure assessment throughout the past six decades. Despite these advancements, to the best of the author's knowledge there are no established methodologies beyond a standard discount cash flow analysis that can carry out a comprehensive economic assessment in a fast, simple and systematic manner, while coping with the limited amount of industrial information available, the plant wide economic impact of control structures, influence of non-routine process disturbances as well as back-up control structures while still providing economically relevant and actionable information. 
The development of this type of a methodology is a necessity as in an industrial setting this type of comprehensive plant wide economic impact analysis is required to convince plant managers to implement/alter current process control operations. In this work we propose a systematic economic assessment methodological approach to address these requirements. To this end, the proposed methodological approach seamlessly combines the economic analysis concept of Net Present Value (NPV) analysis with the process engineering (process safety) concept of Layer of Protection Analysis (LOPA). This combination results in a novel systematic gated methodological approach that enables the comprehensive economic assessment of a given proposed control structure/alternative ${ }^{12}$.

The selection of NPV as the basis of economic evaluation in this methodological approach is influenced by the fact that NPV is one of the most widely used economic analysis methods process industries employ to quantify the benefit of a particular project. NPV analysis is simple and comprehensive and provides a single monetary value as an outcome, which can then be used to make a go/no-go decision. However, the application of NPV in the context of process control structure assessment requires the translation of plant operations information into economic values. During normal operations, the calculation of economic benefits resulting from implementing new process control structures is relatively straightforward, but, calculating the impact of process upsets on the overall economics is more complicated. This is because of the need to take into account the changes in process risk profiles due to the introduction of new process control structures as well as changes in operating points. To this end, the concepts of the industrially accepted LOPA framework can be employed to translate operational information into probability values and economic losses. The LOPA framework was principally developed to carry out plant risk assessments due to major catastrophic events ${ }^{13}$, such as the nuclear disaster 
in Fukushima, Japan. The attractive quality of LOPA is its ability to quantify the economic impact of an event by allowing the calculation of the probability of such an event occurring and estimating the economic consequences of such an event. LOPA also takes into account the influence an independent layer of protection such as a safety backup system or operator intervention would have on the probability and severity of an initiating event, and how the reliability of these systems would change for different operating conditions ${ }^{14}$. The use of LOPA to estimate costs and overall economics based on risk criteria has been carried out in the past. For example, Ramirez-Marengo et al. ${ }^{14}$ looked at a simplified Fuzzy-LOPA model in estimating costs of scenarios, while Johnson ${ }^{12}$ used a LOPA concept to reduce the total cost of process safety equipment. In this proposed methodological approach the authors will adopt the concepts and established methodology of LOPA to translate information related to process upsets, new process control structures and backup controls into probabilities and event costs that can then be used in a comprehensive NPV analysis, which can be used to make an informed decision on process control structure implementation. The proposed methodological approach is intended to be used as a decision aid tool and is intended for use in situations where a control structure is currently in operation or in situations where a control structure has been established as part of a detailed design process.

The rest of this paper is organized as follows. First, an overview of the proposed methodological approach will be presented where the concepts of LOPA and NPV will be modified and redefined to fit the purpose of the proposed methodological approach. That section will be followed by a case study of a high purity industrial methanol distillation unit, where the developed methodological approach will be applied to quantify the economic benefits of two 
proposed control structures against the current control structure employed by an industrial methanol producer. This will be followed by conclusions.

\section{SYSTEMATIC COMPREHENSIVE METHODOLOGICAL ECONOMIC}

\section{ASSESSMENT APPROACH}

The objective of the proposed methodological approach is to allow for the systematic and comprehensive economic assessment of a process control structure, which allows for an informed decision to be made on whether to implement that particular control structure on the process. To this end, a gated methodology is proposed as illustrated in Figure 2. The text following Figure 2 explains the steps and sub-steps in this proposed methodological approach in more detail. 


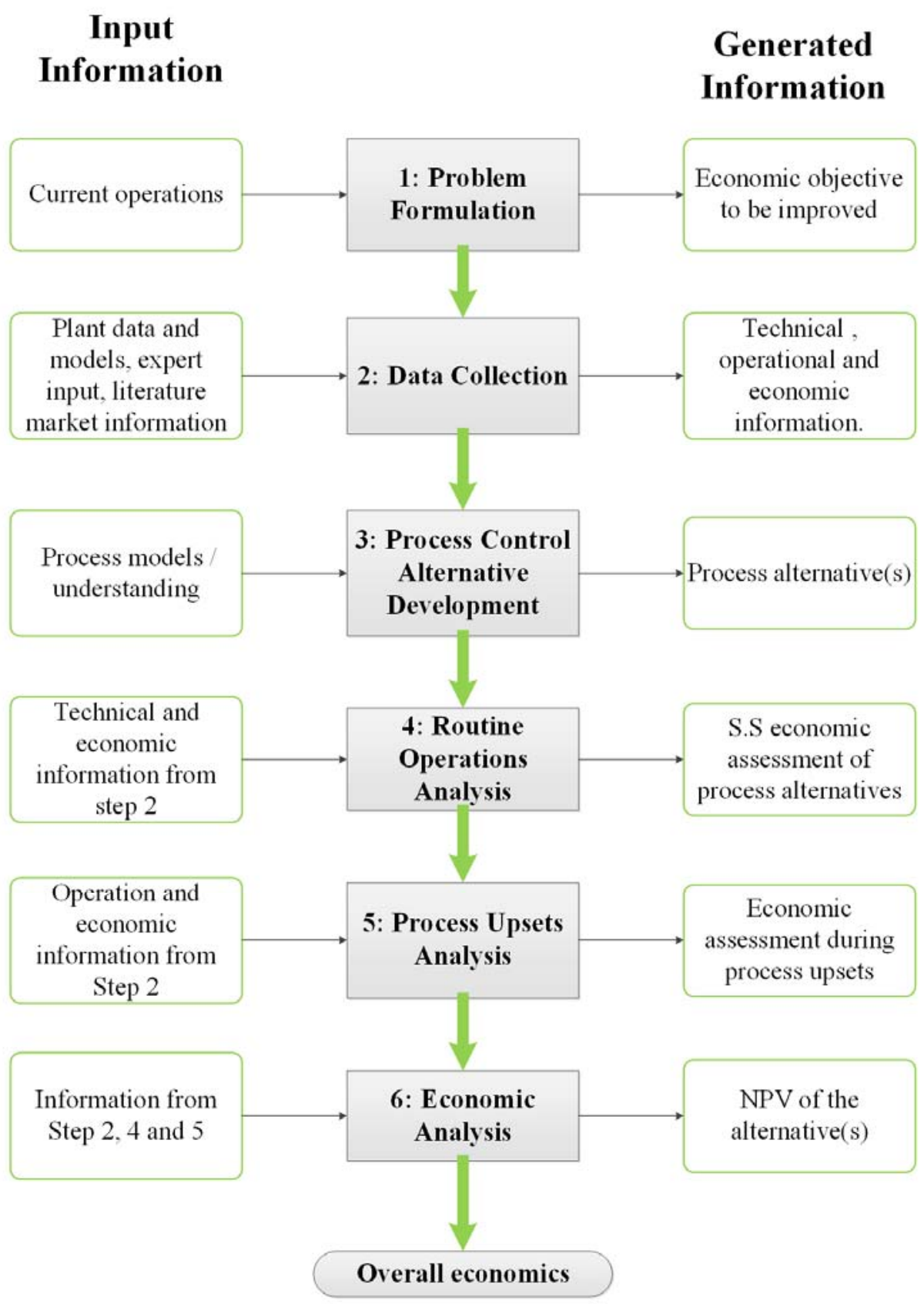

Figure 2: Proposed methodological economic assessment approach 


\subsection{Step 1: Problem Formulation}

The definition of the objectives(s) to be optimized/ improved takes place in the first step. For example, the overall performance objective(s) could be to:

- Improve the production rate

- Improve product recovery rate

- Reduce energy usage per tonne of products

- Combination of the above-mentioned factors

Once the objectives have been defined, these values are translated into economic values in subsequent steps. The identification of one or more objectives also allows for the gathering of relevant plant data and to direct the development of process control structures. The decision to proceed further with this analysis requires the identification of an economic objective as otherwise there will be no "economic" incentive to develop/implement a control structure.

\subsection{Step 2: Data Collection}

In this step, all the relevant information that is required to carry out the following steps in this proposed methodological approach needs to be gathered, processed and systematically organised. To this end, we propose the development of three main knowledge bases that would provide sufficient information for the following steps. These main knowledge bases are:

- Technical information knowledge-base

- Operational information and process upsets knowledge-base

- Economic and market information knowledge-base

\subsubsection{Technical information}


The gathering of process/technical information relevant to the process allows an assessment to be made of the current operating conditions, the current control structure of the process and the identification of both hard and soft constraints. This information can be gathered from:

I. Plant data: This would be the most reliable method to gather information and reflects the actual plant operating conditions. However, it is important that the data is reconciled and validated to be truly useful and reliable.

II. Process models: Validated process models/simulations can also be used in the data gathering exercise. (However, it is also important to emphasize that such models in many industrial applications might not be available, for example industrial scale fermentation processes).

\subsubsection{Operational information and process upsets}

Once baseline technical information is gathered, information relevant to process upsets needs to be collected and organised. The objective of this knowledge base is to identify the severity and frequency of process upsets, and the current operating procedure to counter these upsets. This information can be gathered from:

I. Validated plant data: Many plants have a large amount of historical data which would contain information on previous non-routine process upsets.

II. Process models: A validated process model can be used for process simulation which can also be used to assess the behaviour of both the current control and process alternatives during a process upset (without putting the plant at risk).

III. Key plant personnel: plant managers, engineers as well as operators can play a key role in generating the relevant information, especially when gathering operational information related to how process upsets are handled. 
IV. Literature: Information such as estimating the effectiveness of operators under process upsets.

\subsubsection{Economic and market information}

In order to assess economic benefits of any process control/operations alternative developed, it is necessary to obtain economic and market information that is relevant to translating the technical information to economic information. As such, this step will search and record information such as the value of product leaving the unit operation, cost of raw materials arriving at the unit operation, and cost of utilities. To this end the following information sources can be used:

I. Internal accounting information: The most reliable method of accounting for the cost of products, raw materials, utilities and economics of plant shutdown is internal accounting information as the internal economic models available from the plant operators are specifically adjusted to reflect the true economics.

II. Literature and market information: In case internal accounting information is unavailable, the cost of the above-mentioned variables can be gathered from both literature and the commodities market. In the instance where there is a conflict, information from the commodities market should be used.

Note: Many industrial entities would consider some parts of information in section 2.2, in general, to be sensitive, hence the gathering of such information can prove challenging for an external user.

\subsection{Step 3: Process Control/Operation Alternatives}

Based on the technical information from Step 2, the current operating conditions and control structure of the process needs to established. In situations where the current control structure or 
operations is unspecified this needs to be established prior to proceeding any further, it is recommended to carry out this process through either a rigorous literature search to identify standard control structures and/or industrial information search to identify standard plant control structures for a given unit/plant operation. Based on the objective that is identified for improvement/optimisation (e.g. production rate, energy efficiency or combination) and information gathered in Step 2 (from technical and operational information knowledge bases) new process control structures are developed. This is so the process can operate at an improved state during standard process operations. The criterion by which a go/no-go decision is made to proceed further in the methodology is the development of a new process control alternative. The generation of process control alternatives in this step can be carried out via multiple approaches. The two main approaches are:

- Employing validated process simulation and/or plant data (such as step changes) together with engineering fundamentals and/or industrial insights to develop control structures.

- A rigorous mathematical approach such as mixed integer quadratic programming as discussed by Braccia et al. ${ }^{15}$, or the use of mixed integer linear programing or nonlinear programming as demonstrated in Gutierrez et al. ${ }^{16}$, or the "back-off" concepts outlined in Zumoffen et al., Kookos and Perkins and Psaltis et al. respectively ${ }^{17-19}$.

\subsection{Step 4: Economics of Routine Operations}

The objective of this step is to compare the routine (day-to-day) economic performance of a proposed control structure(s) with the current operating conditions (which will be referred to as 
the base case). To this end, Eq. 1 is utilized to calculate the difference in net profit between the proposed control structure and the base case

$$
\Delta \text { Profit }_{\text {ro }}=\Delta \text { rev }_{\text {ro }}-\Delta r m_{\text {ro }}
$$

Where, $\Delta$ Profit $t_{r o}$ is the difference between $\Delta r e v_{r o}$, the change in revenue and $\Delta r m_{r o}$ the difference in raw material costs between the proposed control structure and the base case. In this methodological approach, "routine operations" is defined as the day-to-day operation. As such, routine process variations (disturbances) experienced by the process are also part of routine process operations.

Note: The calculation carried out in Eq. 1 is a differential profit calculation. Hence, the $\Delta$ Profit $_{\text {ro }}$ between the proposed control and the base case control system is calculated by first identifying differences in mass and energy streams between proposed control and base case and then translating this information into a monetary basis by using economic information gathered in Step 2 (Economic and market information knowledge base). Eq. 1 simplifies the calculation of $\Delta$ Profit $_{\text {ro }}$, as any mass and energy streams that are the same between the proposed control case and the base case can be omitted from the calculation.

\subsection{Step 5: Economics of Process Upsets}

In this step, the economic performance of the proposed control structure during non-routine process upsets will be quantified with respect to the base case. To methodically and systematically carry out this task, algorithm 1 as illustrated in Figure 3 is employed. This algorithm consists of six steps that have been developed with inspiration from a classic Layer of Protection Analysis (LOPA) methodological approach as explained by the Centre for Chemical Safety (USA) ${ }^{13}$. 


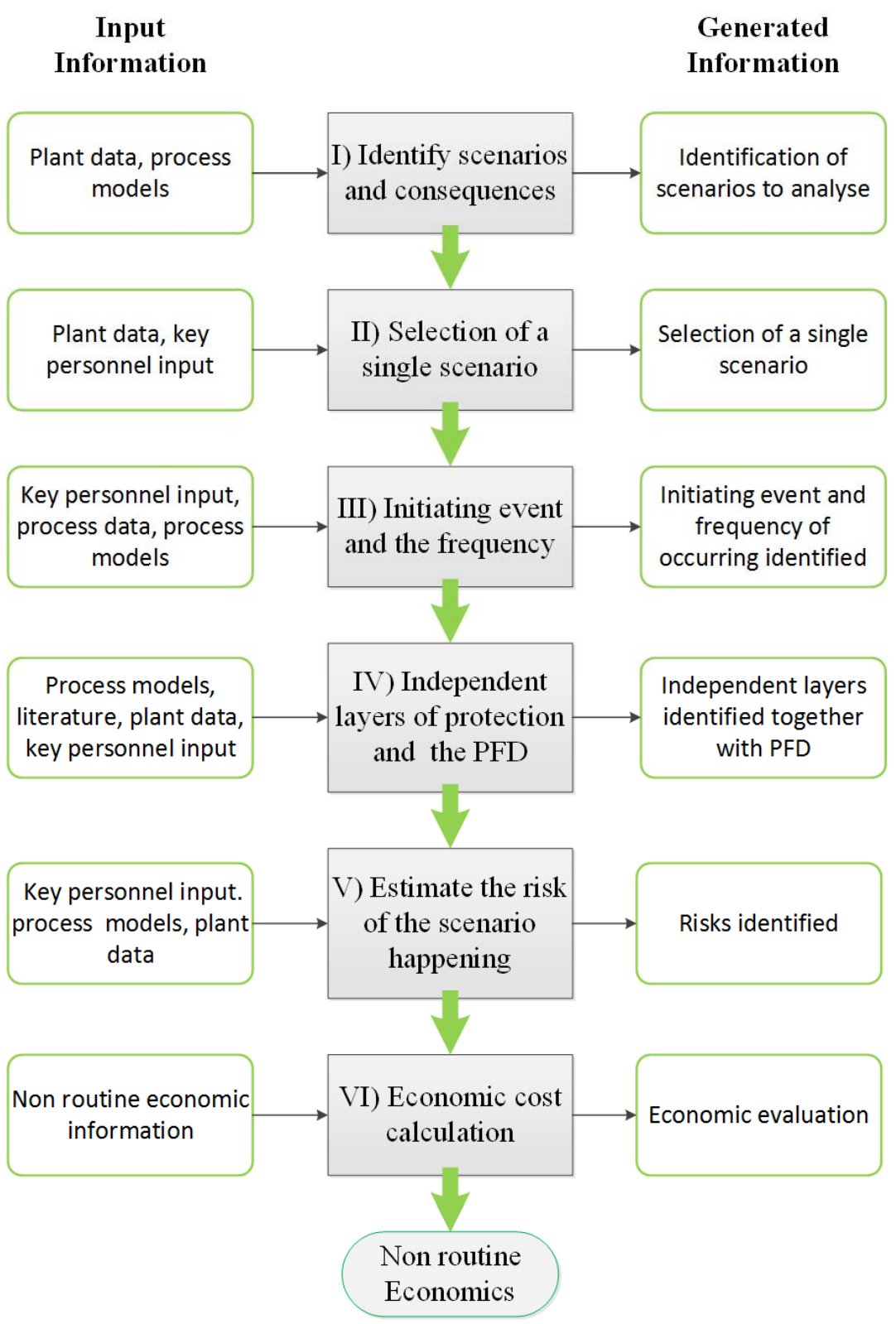

Figure 3: Algorithm 1 - A LOPA inspired approach to calculate the economics of nonroutine process upsets 
Algorithm 1: A LOPA inspired approach to calculate the economics of non-routine process upsets

\section{Step 5(I): Identify initiating events and consequences of scenarios}

In this step, we identify process variable fluctuations of interest by examining past plant data as well as the use of process simulations and models (if available) to identify initiating events. A fluctuation in a process variable will be declared an initiating event if it meets all the following definitions.

- The fluctuation of the process variable must have an impact on the objectives identified in Step 1.

- The process variable fluctuations need to be episodic such that in the day-to-day operations the process variable is stable but can fluctuate episodically. The definition of "episodic" is subjective to each unit operation and needs to be established by key plant personnel.

- The process variable should fluctuate randomly such that the time of occurrence cannot be predetermined by the analysis of past plant data.

In situations where a combination of more than one process variable fluctuation creates this type of initiating event, these process variations can be combined to form a single scenario for further analysis.

NOTE: This step is based on standard LOPA formulation 


\section{Step 5(II): Select a single scenario to analyse further}

If more than one initiating event is identified in Step 5(I), one initiating event should be selected for further analysis. Step 5(III-IV) should be performed sequentially on all scenarios that have an economic impact on operations.

\section{Step 5(III):Identify the initiating event of each scenario and the frequency of such an initiating event}

In this step, plant data is used to identify the underlying cause of process fluctuations in the operation. Once identified the frequency of an initiating event occurring is derived from the plant data. In the context of this methodological approach, it is recommended to calculate the process fluctuation frequency in terms of events per year. This analysis can be complimented by the use of process models and simulations, and the conclusions are to be "sanity checked" by experienced plant personnel.

\section{Step 5(IV):Identify independent layers of protection and quantify the probability of failure on demand}

This step requires the identification of independent layers of protection (ILP) and then the calculation of the probability of failure on demand (PFD) of the identified ILP ${ }^{20}$. In the context of this methodological approach backup control systems together with plant operators would serve as ILP during process upsets. To be called an ILP, each system and operator must be able to function independently from each other and the initiating event. For example, a process control structure that uses a manipulated variable that is not stable during a process upset will not be an ILP. The information regarding PFD of ILP's can be taken from International 
Electrotechnical Commission IEC 61508 international standards for functional safety.

\section{Step 5(V): Estimate the risk of the scenario happening}

This step will combine information collected/estimated in Steps III and IV to calculate the probability of an initiating event causing a process upset in the plant in the presence of ILP's. This risk estimated employing Eq. 3.

$\lambda_{\text {faliure }}=\lambda_{\text {initiation }} \times \lambda_{\mathrm{ILP} 1} \times \lambda_{\mathrm{ILP2}} \times \lambda_{\mathrm{ILPn}} \ldots \times \lambda_{\mathrm{ILPn}}$

where the risk of an initiating event (per year) causing a process upset, $\lambda_{\text {faliure }}$, is equal to the frequency of an initiating event occurring, $\lambda_{\text {initiation }}$ (per year) multiplied by the $\lambda_{\text {ILP }}$ which is the probability an ILP will not be able to contain the initiating event from causing a process upset when required to act (per event).

\section{Step 5(VI): Economic Cost Calculation}

The objective of this step is to compare the economic performance of a proposed process control structure with the current operations strategy during non-routine process upsets. To this end Eq. 3 can be utilized to calculate the difference in net profit between the proposed control structure and the base case:

$$
\Delta \text { Profit }_{\text {nro }}=\Delta \text { Profit }_{I L P d e p}+\Delta \text { Profit }_{\text {ILPfail }}
$$

Eq. 3

Where, the change in profit during non-routine operations, $\Delta$ Profit $_{n r o}$ is equal to the sum of the change in profit during ILP deployment, $\triangle$ Profit $_{I L P d e p}$ and the change in profit of during ILP failure, $\Delta$ Profit $_{\text {ILPfail }}$. Where the change in profit of ILP deployment and failure are 
calculated based on Eq.4 and Eq. 5:

$\Delta$ Profit $_{\text {ILPdep }}=\lambda_{\text {dep.ppc }} \times \Delta$ Profit dep.ppc $-\lambda_{\text {dep.co }} \times \Delta$ Profit $_{\text {dep.co }}$

$\Delta$ Profit $_{\text {ILPfail }}=\lambda_{\text {fail.ppc }} \times \Delta$ Profit $_{\text {fail.ppc }}-\lambda_{\text {fail.co }} \times \Delta$ Profit fail.co $_{\text {Eq. } 5}$

Where Eq. 4 calculates the change in profit due to implementing a process control alternative over the current operations during periods where ILP will be deployed. Eq. 5 calculates the change in profit during ILP Failure.

In eq. $4, \lambda_{\text {dep.ppc }}$ represents the probability of ILP deployment when the proposed control alternative is implemented, while the $\Delta$ Prof $_{i t_{\text {dep.ppc }}}$ is the change in operational profit during an ILP deployment with respect to routine operations as defined in Step 4 if the proposed control alternative is implemented. $\lambda_{\text {dep.co }}$ represents the probability of ILP deployment when the current operations (control structure) is implemented. $\Delta$ Profit $_{\text {dep.co }}$ represents the change in operational profit during an ILP deployment event with respect to routine operations as defined in Step 4 if the current operations (control structure) is implemented.

Similarly in Eq. $5, \lambda_{\text {fail.ppc }} \times \Delta$ Profit fail.ppc $_{\text {represents the probability and change in profit }}$ during ILP failure for the proposed control alternative and $\lambda_{\text {fail.co }} \times \Delta$ Profit fail.co $_{\text {represents }}$ the probability and change in profit during ILP failure for current operations.

\subsection{Step 6: Economic Analysis}

This step involves a comprehensive economic analysis based on the Net Present Value (NPV) analysis method where the economic benefits of the proposed process control structure over 
current operations is quantified. This analysis will generate a single NPV value that can be used by key decision makers to make an informed financial decision on whether to proceed with implementing a process control alternative over the current existing control strategy. NPV analysis works by discounting future cash flows (with an appropriate discount rate) so the benefits received from an investment can be analysed to justify proceeding with the investment.

\subsubsection{Annual Profit}

To calculate the NPV, the annual profit generated by the process alternative will be first calculated using Eq. 6.

$$
\Delta \text { Profit }_{\text {tot }}=\Delta \text { Profit }_{\text {ro }}+\Delta \text { Profit }_{\text {nro }}-\Delta \text { Cost }_{\text {maintenance }} \quad \text { Eq. } 6
$$

Where the overall annual benefit of implementing an alternative control structure over an existing operating strategy, $\Delta$ Profit $_{\text {tot }}$ (per year), is the summation of the economic benefits of introducing an alternative control structure during routine disturbance, $\Delta$ Profit $_{r o}$, and the process upsets (non-routine) operations, $\Delta$ Profit $_{\text {nro }}$, minus the additional maintenance costs of the alternative control structure, $\Delta$ Cost $_{\text {maintenance }}$ (per year).

\subsubsection{Net Present Value}

The net present value of the process control alternatives is then calculated by taking the time value of money of future annual profits generated by implementing process control alternatives and any installation costs based on Eq. 7.

$\mathrm{NPV}=\Delta$ Profit $_{\mathrm{tot}} \times \frac{1-(1+\mathrm{r})^{-\mathrm{n}}}{\mathrm{r}}-\mathrm{IC}$

Eq. 7 
Where $r$ is the discount rate and $n$ is the payback period (in years) and the installation cost of the process alternative is represented by IC. Most industrial companies would have internal values for $r$ and $n$. If the NPV calculated in Eq. 7 is positive, the economics dictate that the implementation of the process control alternative will be economically beneficial and hence should be undertaken. The NPV calculation also allows competing process control alternatives to be compared against each other, with process control alternatives with higher NPV having a better economic performance in comparison. It is important to note that the discount rate $r$ in the context of engineering projects is used to describe the relative risk associated with a project as well as the time value of future revenues. As such, a high discount rate can be employed to capture the economic risk associated with implementing a given process alternative and can be adjusted accordingly. In an industrial setting, the best estimate for the initial cost of installing a process control structure can be obtained by requesting a quotation from an engineering procurement contractor, process control equipment vendor or a process control consultant. In a situation where the initial costs cannot be accurately estimated the present value of the economic benefits can be calculated using $\Delta$ Profit $_{\text {tot }} \times \frac{1-(1+r)^{-n}}{r}$ as this value reflects the maximum initial cost expenditure that will still return a non-negative NPV.

\subsubsection{Sensitivity Analysis}

While the proposed methodological approach does not explicitly require the performance of a sensitivity analysis it can be beneficial to perform such an analysis. This can be especially relevant if economic/market information used in the analysis is subject to fluctuation due to market forces and/or when there is uncertainty in the input assumptions and process data. 


\section{CASE STUDY: HIGH PURITY METHANOL DISTILLATION}

In this section, the application of the methodological approach presented in section 2 is highlighted on an industrial case study of a high purity methanol distillation unit. Two process control alternatives were compared against the current process control structure in this case study.

\subsection{Case study background}

The operation of a high purity, multi-component industrial methanol distillation unit is a fine balancing act. On one hand, the operators need to ensure the ethanol impurities in the distillate methanol stream are kept below the Federal AA grade specification of $10 \mathrm{ppm}$. On the other hand, the operators need to maintain an adequate product recovery rate $(>98 \%)$ for an economically favourable operation. Table 1 displays the steady state mass balance of the column during the current steady-state operation.

In addition to the product recovery and purity specifications, the bottom stream of the column must contain less than 10ppm of methanol as this allows the methanol producer to discharge this stream with minimal treatment. From a design point of view, this is achieved by using a small side draw which is used to discharge most of the ethanol entering the column. As a result of these demanding requirements as well as the presence of the side draw, the control of this type of distillation unit can be difficult due to the complex process dynamics, as discussed by Udugama et al. ${ }^{21}$. In addition, the steam flow rate to the distillation unit can exhibit unstable non-routine process disturbances (as discussed in detail in the following analysis). 
Table 1: Steady-state mass balance of the methanol refining unit

\begin{tabular}{|c|c|c|c|}
\hline \multirow{4}{*}{ Feed } & Mass Flow & $\mathbf{1 4 2 . 5}$ & $\mathbf{T} / \mathbf{h r}$ \\
\cline { 2 - 4 } & Methanol composition & 82.5 & $\mathrm{wt} \%$ \\
\cline { 2 - 4 } & Ethanol composition & 150 & $\mathrm{ppm} \mathrm{wt}$ \\
\cline { 2 - 4 } & Water composition & 17.5 & $\mathrm{wt} \%$ \\
\hline \multirow{4}{*}{ Distillate } & Mass Flow & $\mathbf{1 1 5 . 2}$ & $\mathbf{T} / \mathbf{h r}$ \\
\cline { 2 - 4 } & Methanol composition & 99.9 & $\mathrm{wt} \%$ \\
\cline { 2 - 4 } & Ethanol composition & 5.5 & $\mathrm{ppm} \mathrm{wt}$ \\
\cline { 2 - 4 } & Water composition & 60 & $\mathbf{p p m ~ w t}$ \\
\hline \multirow{5}{*}{ Bide draw } & Mass Flow & $\mathbf{3}$ & $\mathrm{wt} \%$ \\
\cline { 2 - 4 } & Methanol composition & 78.3 & $\mathrm{wt} \%$ \\
\cline { 2 - 4 } & Ethanol composition & 0.6 & $\mathrm{wt} \%$ \\
\cline { 2 - 4 } & Water composition & 21.1 & $\mathbf{T} / \mathbf{h r}$ \\
\hline \multirow{3}{*}{ Bottoms } & Mass Flow & $\mathbf{2 4 . 3}$ & $\mathrm{wt} \%$ \\
\cline { 2 - 4 } & Methanol composition & 5 & $\mathrm{ppm} \mathrm{wt}$ \\
\cline { 2 - 4 } & Ethanol composition & 0 & $\mathrm{wt} \%$ \\
\cline { 2 - 4 } & Water composition & 99.4 & \\
\hline
\end{tabular}

\subsection{Current Operations}

As illustrated in Figure 4, the current control structure employs no advanced process control. Instead, the process is controlled by simple feedback and cascade control loops, while the operators control the reboiler duty to the column manually (via the steam flow rate). As shown in Table 1, the column is typically operated at product ethanol composition of $5.5 \mathrm{ppm}$ using the controller (XC) to maintain product purity. With the Federal AA grade ethanol specification at $10 \mathrm{ppm}$ ethanol, the current operation allows the operators to negate daily process disturbances without considering the complex process dynamics while also providing a significant process buffer during non-routine process disturbances. However, this action reduces the product recovery rate of the column to $98 \%$. 


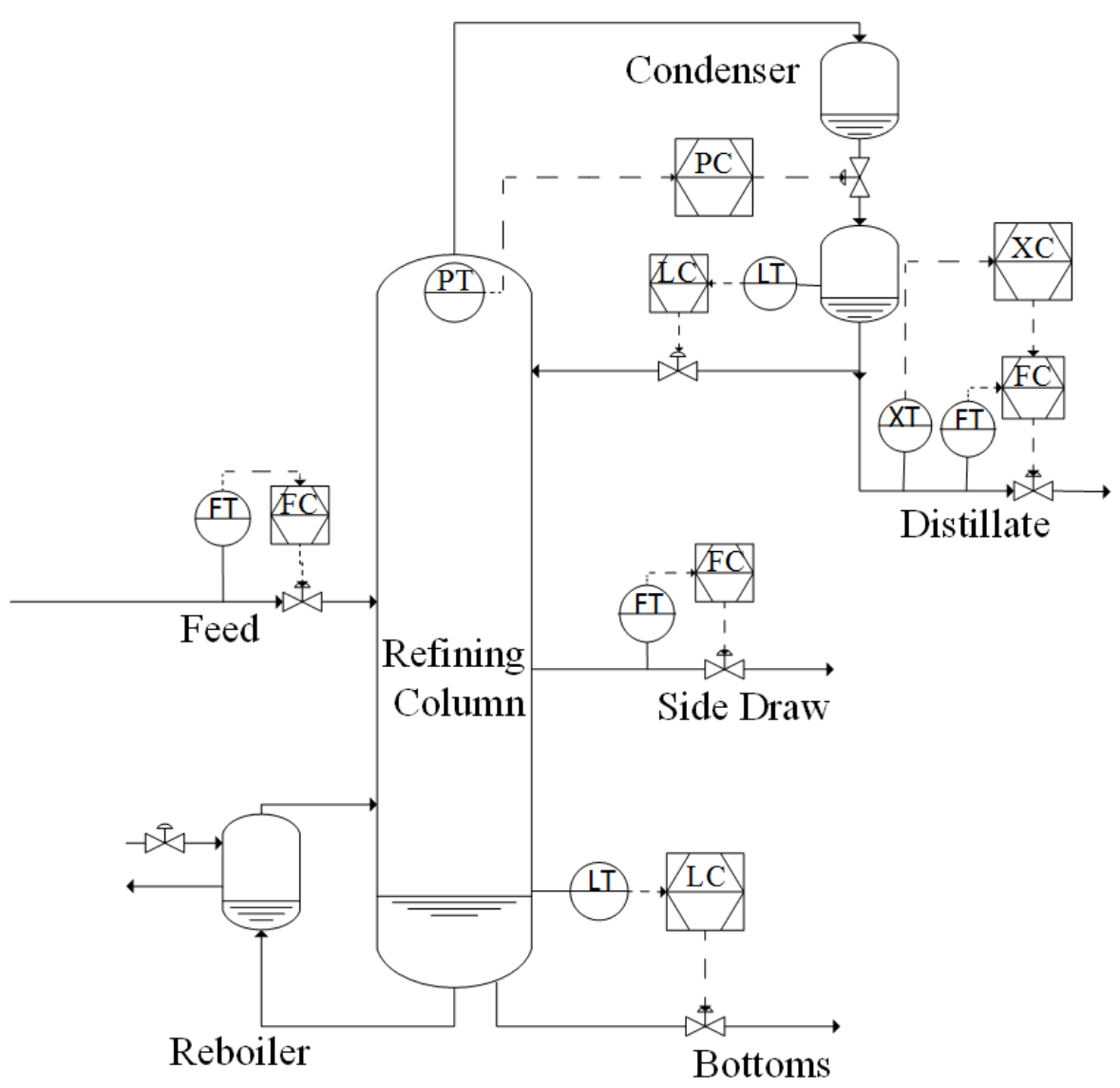

Figure 4: A simplified diagram of the methanol distillation unit, with the current control structure.

Note: The condenser in this particular distillation column is a flooded condenser arrangement; as such, controlling the condensate flow from the condenser directly influences the cooling duty available. The cooling water to this condenser is not shown in the diagram as it is kept at a constant flow rate. 


\subsection{Process Control Alternative A}

In Udugama et al. ${ }^{21}$ the authors focused on the operations of methanol distillation columns using the same plant data used in the case study to develop a validated process simulation. The objective of this work was to develop practical process control structures that can be employed to operate the column at product recovery levels of $99.5 \%$ while still being able to counter day-today process disturbances. To this end, two process control structures were developed, out of which the decentralised control structure developed is displayed in Figure 5. In this instance, two supervisory controllers were implemented, namely the Recovery Constraint Controller (RCC) and the Dynamic Reboiler Controller (DRC). The RCC maintains the mass balance in the column while DRC ensures the overall energy balance is maintained. This supervisory control structure was then put through disturbance tests where it was established that it can maintain on specification operation of the methanol distillation unit under various feed flow disturbances. The reasons for implementing this type of control structure is the unreliability of the column temperature profile in a multi-component, high-purity distillation process in estimating the product quality, when the product purity is based on the middle boiling component fraction present in the product (Ethanol in a Methanol/Water mixture). This has been discussed and established in detail by Udugama et al. ${ }^{22,21}$. These works also discusses the process modelling challenges associated with modelling the dynamics of such a multi-component high-purity distillation process. While Udugama et al. ${ }^{22}$ explains the complexities involved with measuring the composition of the product draw and the possibilities of stream multiplexing to utilise product gas chromatographs (routinely used to monitor the high purity product methanol in industry) to monitor other stream compositions such as the side draw to keep monitoring and operations cost down for proposed control alternatives. The steady state modelling aspects have 
also been discussed by Kraller et al. ${ }^{23}$ while other interesting aspects of this particular type of methanol distillation columns have been discussed by some of the authors involved in this work in ${ }^{24-27}$. It is important to note that a model predictive control was also developed in Udugama et al. ${ }^{21}$ alongside the decentralised control structure illustrated in Figure 5. For this case study the decentralised control structure was selected as it had a similar performance to the model predictive controller structure while being simpler to implement and maintain.

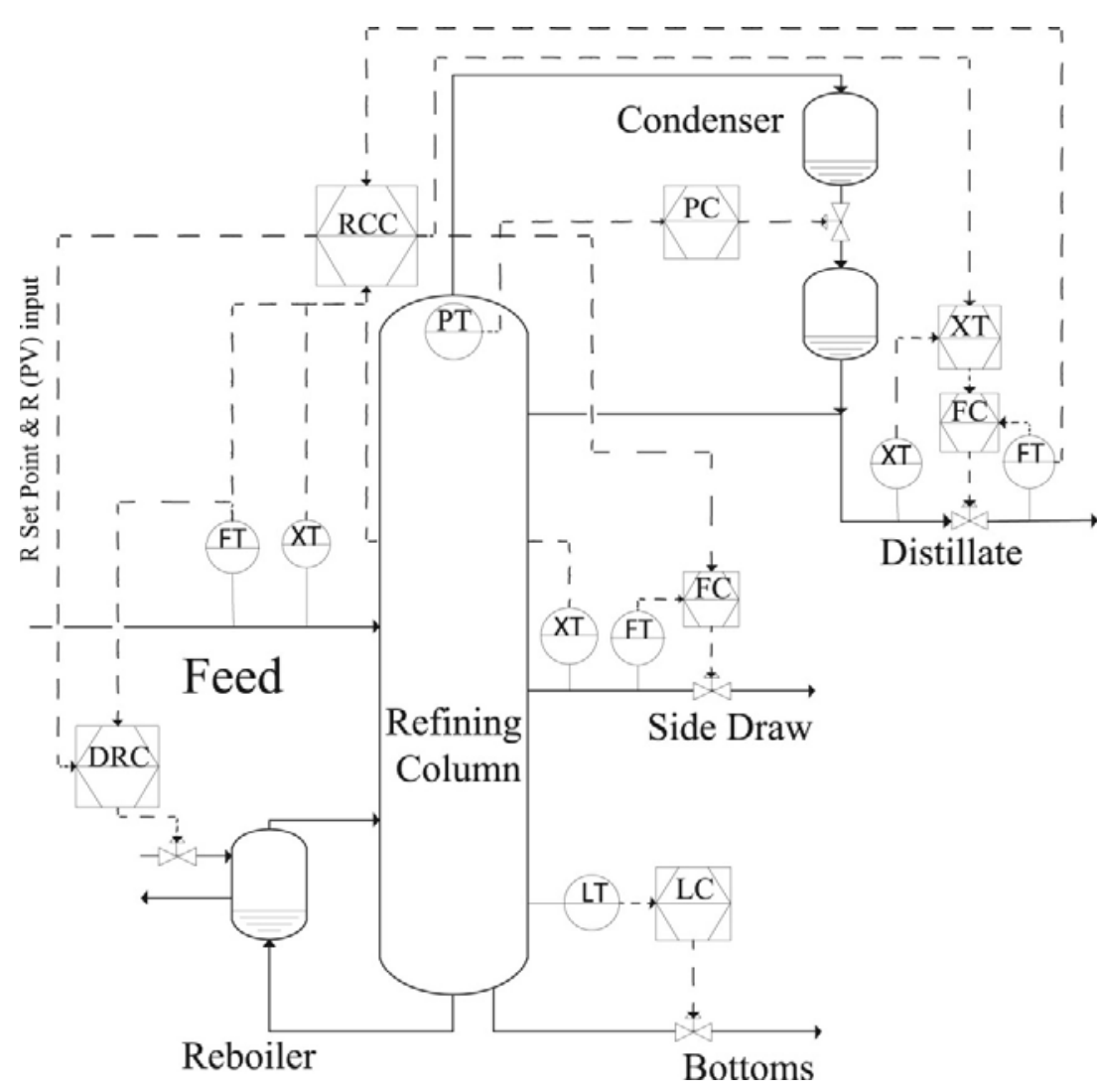

Figure 5: Simplified process control diagram of the control structure developed by Udugama et al. ${ }^{21}$ (Process control alternative A)

Note: The level in the reflux drum is still controlled by manipulating the reflux flow but has been omitted from the Figure to declutter the diagram. 
This process control structure will be known as process control alternative $\mathrm{A}$ in the forthcoming analysis. It is important to note that process control alternative A requires operators to intervene during non-routine process upsets as the control strategy uses steam as a manipulated variable.

\subsection{Process Control Alternative B}

Process control alternative B consists of two separate control structures. The primary control structure is the same as process control alternative A (as illustrated in Figure 5). This structure is then further supplemented by a backup process control structure that was introduced by Udugama et al. ${ }^{27}$ and is illustrated in Figure 6. Similar to the primary control structure, the backup control structure employs RCC to control the materials balance while combining this with a flow controller (FC), which controls the feed flow rate into the column based on steam flow rate. As such, in process control alternative $\mathrm{B}$, the operators do not need to intervene during a non-routine process steam flow upset as the backup control strategy will take over the control of the process. 


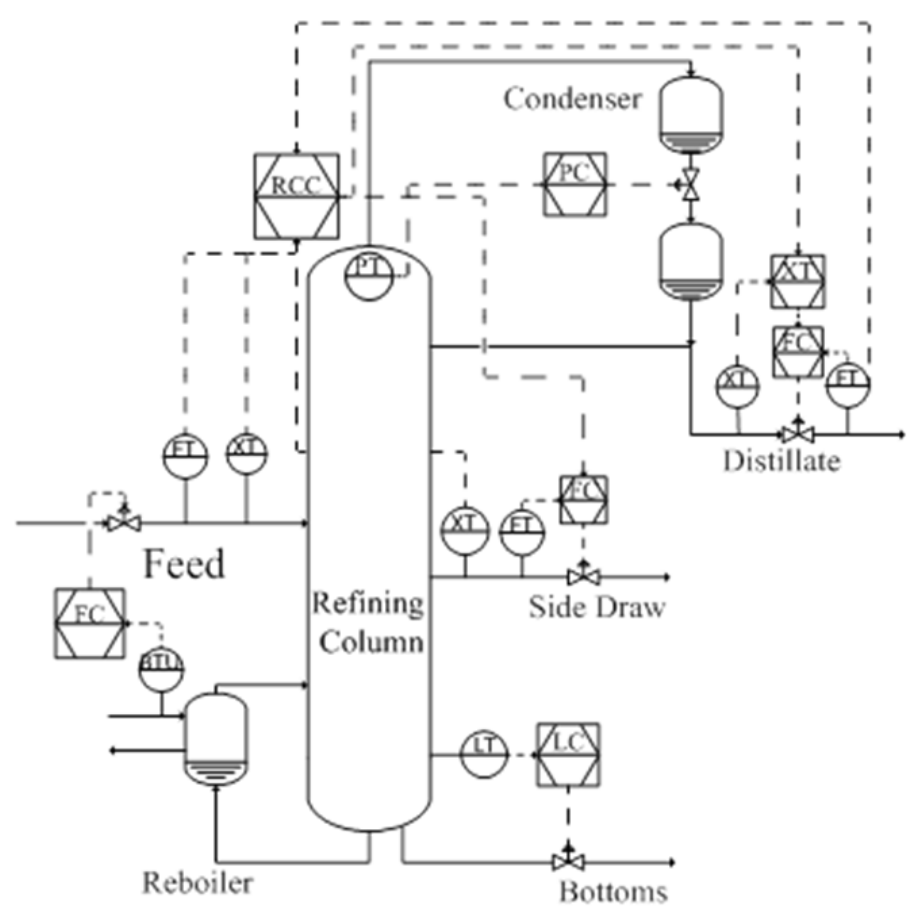

Figure 6: Backup process control structure as introduced in Udugama et al. ${ }^{27}$, (Process

\section{Control Alternative B)}

Note: The level in the reflux drum is still controlled by manipulating the reflux flow but has been omitted from the Figure to declutter the diagram.

\subsection{Application example}

\subsubsection{Step 1: Problem Formulation}

The objective of this case study is maximising the overall revenue of the distillation unit while taking into account product limitations and other process constraints discussed previously. In addition, the average feed flow rate and feed composition are constrained to the values recorded in Table 1. Moreover, reducing the economic losses during non-routine process upsets can also aid with improving overall revenue. Considering these objectives, any potential process control improvement should: 
- Operate the column at a product recovery rate of $>98 \%$ while achieving the specified production.

- Reduce the overall economic losses during non-routine process disturbances

\subsubsection{Step 2: Data Collection}

During this case study, the authors had access to plant data, as well as a dynamic process simulation, market information, and key plant personnel. All these resources were used in the data gathering as discussed in section 2.2.

To this end, plant data gathered was analysed to find the causes of non-routine process upsets that create off-specification production of methanol in the column. This data was then analysed using a principal component analysis (PCA) ${ }^{25}$. Based on this analysis, the off-specification methanol production was traced back to a non-routine upset in the steam flow. Figure 6 illustrates the relationship between product ethanol concentration and the overall reboiler duty where it can be clearly seen that the off-specification ethanol production is correlated with overall reboiler duty. In this instance, the reboiler duty was calculated from the temperature, pressure and flow rate data of the steam and condensate streams. This action was taken as the temperature, pressure and flow rate information of steam and condensate streams did not show a satisfactory correlation to the off-specification production periods as detailed in ${ }^{25}$.

Upon further investigation it was identified that the steam supply itself can be unstable (i.e. can vary due to other factors). This is because the steam in this methanol production plant is produced as a part of the heat integration loop where heat is extracted by cooling down the flue gas and product gas from a syngas reforming process. As a result, disturbances in this process can cause the steam supply quality to vary. 
Information related to routine and non-routine process operations will be introduced in the following sections.

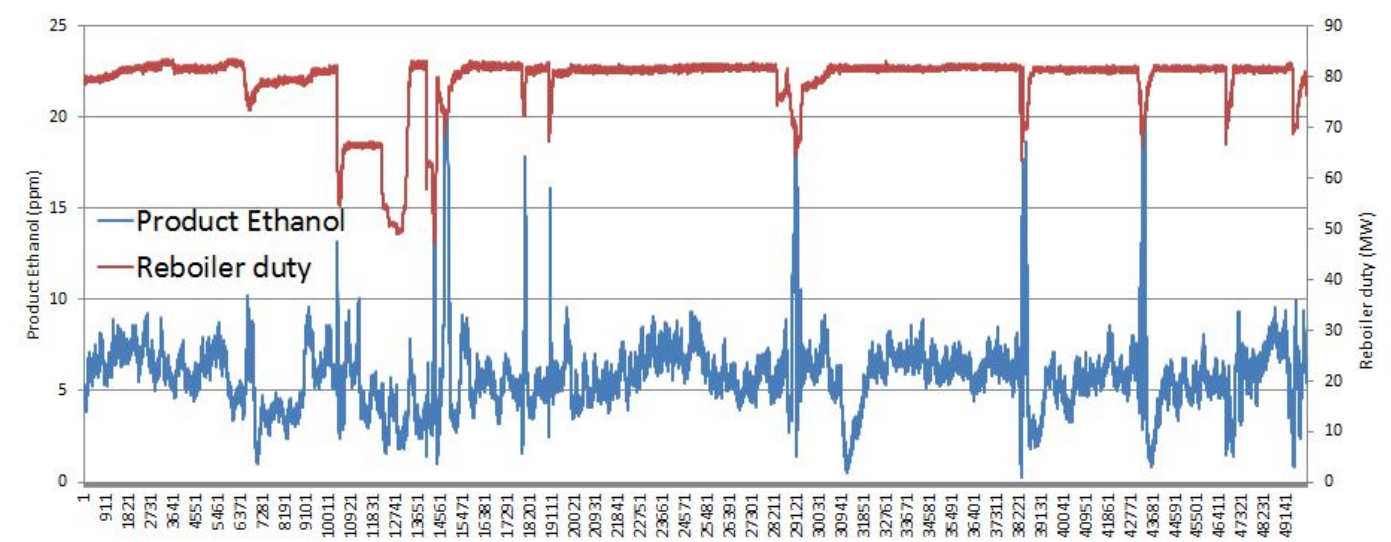

Figure 7: Product ethanol concentration versus reboiler duty. (Time span not displayed for confidentiality reasons)

Note: a detailed discussion of the features of Figure 7 has been carried out in ${ }^{25}$,

\subsubsection{Step 3: Process Control/Operations Alternatives}

This step requires the identification of process control or operational alternatives that achieve the objectives set out in Step 1. In the context of this case study, we have already identified the two process control alternatives and the current operation scheme at the beginning of the case study section. These are:

1. Current Operations $(\mathrm{CO})-$ described in section 3.2

2. Process Control Alternative A (AA) - described in section 3.3

3. Process Control Alternative $\mathrm{B}(\mathrm{AB})$ - described in section 3.4 


\subsubsection{Step 4: Economics of Routine Operations}

In this instance both $\mathrm{AA}$ and $\mathrm{AB}$ will have the same process control structure operating the column during routine operations. Based on both plant trials and process simulation data the supervisory control structure used in both $\mathrm{AA}$ and $\mathrm{AB}$ will operate the distillation unit at a recovery of $99.5 \%$ during routine operations. Both $\mathrm{AA}$ and $\mathrm{AB}$ will increase methanol production in this column by $2 \mathrm{~T} / \mathrm{hr}$ at no extra feed or energy costs.

However, a detailed look into plant operations with key plant personnel showed that the methanol in the side draw reduces in high recovery operations and, as the side draw is usually recycled back to the reformer unit in the methanol production operations, more natural gas is required to operate the facility at current rates. Based on available plant data, we can calculate that for every tonne of methanol absent in the side draw we will need an extra 19GJ of natural gas. In the calculation of the profit generated by the proposed process control alternatives, the requirement of extra natural gas needs to be factored in.

Based on this information, a market methanol price of $330 \mathrm{USD} /$ ton and a natural gas price of 5 USD/GJ (at the time of performing the study), the economic benefit of routine process operations can be calculated as illustrated in Eq. 8 .

$$
\begin{aligned}
& \Delta \text { Profit }_{r o}=\Delta r e v_{r o}-\Delta r m_{r o} \\
& \Delta \text { Profit }_{\text {ro }}=2 \frac{T}{h r} \times 8460 \frac{h r}{\text { year }} \times 330 \frac{U S D}{T}-2 \frac{T}{h r} \times 19 \frac{G J}{T} \times 8460 \frac{h r}{\text { year }} \times 5 \frac{U S D}{T} \\
& \Delta \text { Profit }_{\text {ro }}=3.9 \text { Million USD }
\end{aligned}
$$




\subsubsection{Step 5: Economics of Process Upsets}

\section{Step 5 (I): initiating events and consequences of scenarios}

Based on the plant data analysis conducted in Step 3 of the case study, the initiating cause has been identified to be a sudden reduction in the reboiler duty due to an unstable steam supply. For the purpose of this case study, we define an initiating event as a loss in steam supply which results in the production of methanol with $>10 \mathrm{ppm}$ ethanol impurities if no remedial process control action is taken.

\section{Step 5 (II): Select a single scenario to analyse further}

In this instance, we will focus on the pre-identified scenario of unstable steam supply which causes the production of off-specification product ethanol.

Step 5 (III): Identify the initiating event of each scenario and the frequency of such an initiating event

In industrial methanol plants, steam used in operating the distillation unit is mainly raised by recovering waste heat from the reforming process. Any process fluctuations in the reforming process will influence the stability of the steam loop. With little/no ability to raise additional steam, these process fluctuations will influence the operations of the distillation units.

\section{$\underline{\text { Current Operations }}$}

In current operations, the distillation column is operated at a product ethanol specification of 5.5 ppm. Even with this process buffer, the plant will produce off-specification product twice per year.

\section{Process control alternative A}

Operating the plant at a higher recovery rate of $99.5 \%$ and at a product ethanol specification of $8 \mathrm{ppm}$ increases the frequency of the initiating event to between 4-5 times per year. This value is 
calculated based on plant data, process models as well as input from operations and management. The reason for the higher number of initiating events is the result of a reduction in process buffer and the increase in sensitivity of the product ethanol concentration to steam supply changes at higher levels of recovery.

\section{Process control alternative $B$}

The initiating events for process control alternative B will be the same as for process control alternative A.

Step 5 (IV \& V): Identify ILP and its PFD, estimate the risk of the scenario happening with ILP

In this case study, we have carried out both Steps IV \& V of the methodology together as this enables a better presentation of the information to the reader for comparison purposes. However, the actual analysis of each ILP alternative was carried out sequentially. To this end, we assessed the three process alternatives identified at the beginning of the case study.

\section{$\underline{\text { Current operations }}$}

In the current operations, the plant operators are the only independent layer of protection. In situations where the operator can intervene on time and successfully, the operators will:

- Reduce feed rates to the column to $50 \%$ of normal rates for about 12 hours

- Operate at $75 \%$ of capacity for another 12 hours.

These actions guarantee on-specification products and allow for a return to full rate operations within 24 hours. In comparison, if the operators fail to intervene in time, the product ethanol specification will exceed $10 \mathrm{ppm}$ which results in a suspension of column operations (column trip) and results in 72 hours of loss in production capacity. 
In terms of the probability of failure on demand (PFD), the large process buffer between product ethanol composition and specification (5.5 ppm vs $10 \mathrm{ppm}$ ) means that the operators have a 20 25 minute time buffer to act accordingly. Based on the operator PFD data presented in ${ }^{28}$ the PFD of the operators is estimated to be 0.05 times per event. Based on this information we can calculate $\lambda_{\text {failure }}$ to be as follows:

$$
\begin{aligned}
& \lambda_{\text {failure }}=\lambda_{\text {initiation }} \times \lambda_{\text {ILP1 }} \times \lambda_{\text {ILP2 }} \times \lambda_{\text {ILPn }} \ldots \times \lambda_{\text {ILPn }} \\
& \lambda_{\text {failure }}=2 \frac{\text { events }}{\text { year }} \times 0.05 \frac{\text { failures }}{\text { event }} \\
& \lambda_{\text {failure }}=0.1 \frac{\text { faliures }}{\text { year }}
\end{aligned}
$$

\section{Process Control Alternative A}

Similar to current operations, the AA scheme requires the operators to intervene during routine process operations and hence has similar outcomes to the one discussed above if the operators are able to intervene in time as well when they are unable to intervene on time.

However, the process buffer time will be smaller at 10 minutes, as the column is operated at 8 ppm product ethanol composition and at high recovery. As a result, the PFD is estimated based on ${ }^{28}$ to be 0.1 times per event. With this information we can calculate the probability of failure $\lambda_{\text {faliure }}$ as follows:

$$
\begin{aligned}
& \lambda_{\text {failure }}=\lambda_{\text {initiation }} \times \lambda_{\mathrm{ILP} 1} \times \lambda_{\mathrm{ILP} 2} \times \lambda_{\mathrm{ILPn}} \ldots \times \lambda_{\mathrm{ILPn}} \\
& \lambda_{\text {failure }}=4.5 \frac{\mathrm{events}}{\text { year }} \times 0.1 \frac{\text { failures }}{\text { event }} \\
& \lambda_{\text {failure }}=0.45 \frac{\text { failures }}{\text { year }}
\end{aligned}
$$




\section{$\underline{\text { Process Control Alternative B }}$}

In comparison to $\mathrm{CO}$ and $\mathrm{AA}, \mathrm{AB}$ has different process outcomes during non-routine process upsets. This is because $\mathrm{AB}$ has a backup control structure to operate the column during steam supply disturbances. The backup control strategy forms the first ILP in AB. If the backup control scheme is in operation, the loss in production will be negligible (as the column will operate at optimal production rate for a given steam input, thus will return to full rates the moment the steam flow returns to normal). In case the backup controller (first ILP) fails, the operators (second ILP) can intervene and maintain a steam/feed ratio which is an input to the backup control strategy. Based on steam flow data and plant operations input we estimate that the operators will operate the process at $75 \%$ capacity for an average of 6 hours, before transitioning to full rates.

If both ILP's fail, then the column operations will be suspended and will result in a production capacity loss of 72 hours similar to current operations.

In terms of probability of failure, the operator stays the same as AA at 0.1 failures per event as they have a similar process buffer time to act if the backup system fails while the backup process control structure PFD is estimated to be 0.01 based on IEC 61508 standards. Based on this, the probability of failure $\lambda_{\text {failure }}$ can be calculated as follows:

$$
\begin{aligned}
& \lambda_{\text {failure }}=\lambda_{\text {initiation }} \times \lambda_{\mathrm{ILP} 1} \times \lambda_{\mathrm{ILP} 2} \times \lambda_{\mathrm{ILPn}} \ldots \times \lambda_{\mathrm{ILPn}} \\
& \lambda_{\text {failure }}=4.5 \frac{\text { events }}{\text { year }} \times 0.01 \frac{\text { failures }}{\text { event }} \times 0.1 \frac{\text { failures }}{\text { event }} \\
& \lambda_{\text {failure }}=0.0045 \frac{\text { failures }}{\text { event }}
\end{aligned}
$$




\section{Step 5 (VI): Economic Cost Calculation}

The objective of this step is to calculate the change in profit that occurs during non-routine process operations between the proposed process control alternative and current operations. With respect to this case study, we will use the following estimates to carry out this calculation:

- Net margin from production is estimated to be 120 USD per metric tonne.

- An average production rate of 115 tonnes per hour.

The net margin from production of 120 USD per metric tonne is an industrial value that is used by the industrial methanol producers that factors in the cost of recovering, storing and redistilling off-specification methanol. Based on this information and the information gathered thus far in the LOPA-based, non-routine analysis, the economic performance of each of the three scenarios can be calculated. Based on the concept and methodology outlined in Section 2, Table 2 illustrates the change in profit of $\mathrm{AA}$ and $\mathrm{AB}$ compared to $\mathrm{CO}$.

Table 2: Economic performance of $\mathrm{AA}$ and $\mathrm{AB}$ during non-routine process upsets in comparison to current operations

\begin{tabular}{|l|c|c|c|}
\hline & CO & AA & AB \\
\hline ILP Failure & 72 & 72 & 72 \\
Loss of full rate production hours & 115 & 115 & 115 \\
\hline Production at full rates (T/hr) & 8280 & 8280 & 8280 \\
\hline Loss of production (T) & 120 & 120 & 120 \\
\hline Net margin of production loss (USD/T) & 993,600 & 993,600 & 993,600 \\
\hline Economic loss per failure (USD/p.a) & $\mathbf{9 9 , 3 6 0}$ & $\mathbf{4 4 7 , 1 2 0}$ & $\mathbf{4 , 4 7 1}$ \\
\hline Economic loss per year (USD/p.a) & & & \\
\hline
\end{tabular}




\begin{tabular}{|l|c|c|c|}
$\therefore$ PProfit ILP Failure per year & $\mathbf{\$ 0}$ & $\mathbf{\$ - 3 4 7 , 7 6 0}$ & $\mathbf{\$ 9 4 , 8 8 9}$ \\
\hline ILP deployment & & & \\
Loss of full rate production hours & 9 & 115 & 115 \\
\hline Production at full rates (T/hr) & 115 & 1035 & 172.5 \\
\hline Loss of production (T) & 1035 & 120 & 120 \\
\hline Net margin of production loss (USD/T) & 120 & 124,200 & 20,700 \\
\hline Economic loss per failure (USD/failure) & 124,200 & $\mathbf{5 0 3 , 0 1 0}$ & $\mathbf{9 3 , 0 5 7}$ \\
\hline Economic loss per year (USD/p.a) & $\mathbf{2 3 5 , 9 8 0}$ & $\mathbf{- 2 6 7 , 0 3 0}$ & $\mathbf{1 4 2 , 9 2 3}$ \\
\hline$\therefore \Delta$ Profit ILP Failure (USD/p.a) & - & $\mathbf{\$ - 6 1 4 , 7 9 0}$ & $\mathbf{\$ 2} 237,812$ \\
\hline$\Delta$ Profit nro per year & - & 9 & \\
\hline
\end{tabular}

\subsubsection{Step 6: Economic Analysis}

In this step the output of Steps 4 and 5 together with process control alternative implementation costs should be used to calculate the NPV. However, in this case study we will calculate the present value of the future cash flows of the project without the cost of implementation. As such the calculated NPV value will be used to estimate the maximum bearable cost of implementing process control alternative $\mathrm{AA}$ or $\mathrm{AB}$.

To carry out this step it is important to factor in the time value of money which will be done by employing a discount rate. In this case study, we have selected a discount rate of $25 \%$ per year, which means the value of future revenues will be discounted $25 \%$ each year. We have also selected a project payback period of 5 years, which means we will only consider profits up to 5 years in the future. These values are relatively aggressive and act as economic safety factors. Table 3 illustrates the overall economics of the case study. 
Table 3 Overall economic performance of $A A$ and $A B$ versus current operations (in USD)

\begin{tabular}{|l|l|l|}
\hline & $\mathrm{AA}$ & $\mathrm{AB}$ \\
\hline$\Delta$ Profit routine operations & $3,976,000$ & $3,976,000$ \\
\hline Profit non routine operations & -614790 & 273812 \\
\hline$\Delta$ Profit per year & $3,361,210$ & $4,249,812$ \\
\hline NPV (5 year payback @ $\mathbf{2 5 \%}$ discount rate) & $\mathbf{9 , 0 3 9 , 2 3 5}$ & $\mathbf{1 1 , 4 2 8 , 9 3 4}$ \\
\hline
\end{tabular}

Based on these NPV values it can be clearly concluded that both AA and AB will add a significant economic benefit to the economic performance of the high purity distillation columns analysed. From the NPV it can also be concluded that:

- In comparison to current operations the future additional cash flows of process control alternative $\mathrm{AA}$ and $\mathrm{AB}$ has a present value of USD 9 million and 11.4 Million respectively.

- Implementation of AA makes economic sense if the installation cost is lower than USD 9 million.

- Control structures $\mathrm{AA}$ and $\mathrm{AB}$ both work based on supervisory control structures and are based on technology that is available in industry; however, they have not been implemented in this configuration previously. To factor this economic risk a conservative discount rate of $25 \%$ was used. 
- While redundancy/backup is standard in safety critical process systems, in operational systems there is always a debate on whether implementing a backup control is economically beneficial. In this particular case study implementation of a backup control structure (thus $\mathrm{AB}$ ) makes economic sense if the backup control implementation costs less than USD 2.4 million.

- The economic implications of both the routine operations as well as non-routine process upsets play a noticeable role in the final financial economic outlook.

- The proposed methodology allows key personnel to systematically pool resources together in a key decision-making process and allows them to extract plant data as well as use process simulations in estimating key variables that have a significant influence on the NPV calculation.

\section{6 Sensitivity Analysis}

The calculation of the NPV for the two process alternatives AA and AB over current operations requires both key economic and operational inputs. These variables while being accurate can easily change and are subject to change due to economic conditions or overall plant operating strategy. As such it is necessary to understand the influence that variations in key economic and operational inputs would have on the calculated NPV for the process alternatives.

In order to understand the influence economic changes would have on the NPV calculations the influence of the economic variables of methanol sales price, natural gas cost, cash discount rate and net margin on the loss of production have been plotted against the NPV in Figure 7. 


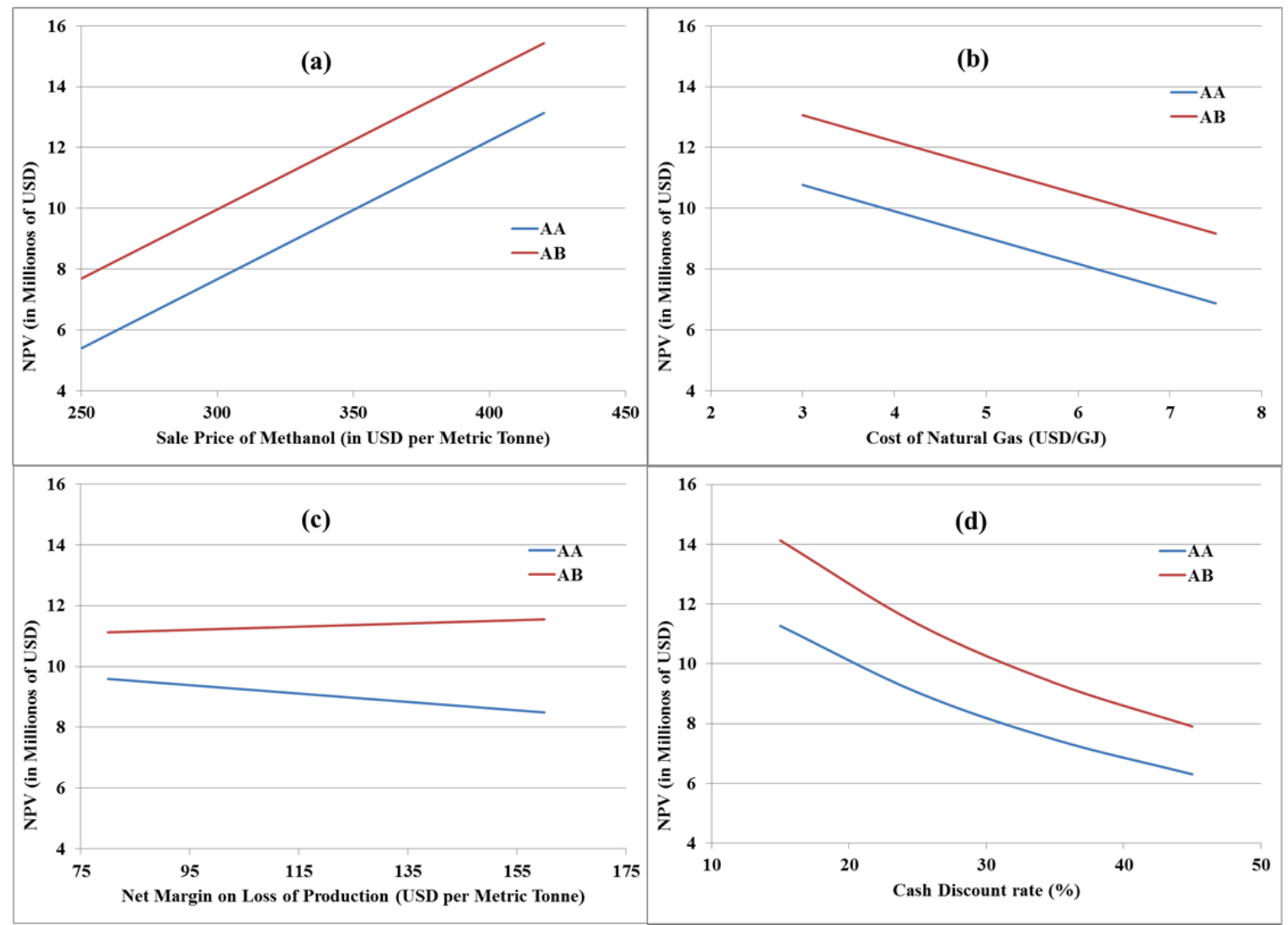

Figure 8: Variation of incremental NPV for control alternatives AA and AB for changes in economic variables (a) Sales price of methanol, (b) Cost of natural gas, (c) Net margin of loss of production, (d) Cash discount rate.

From analysing the plot of NPV versus sale price of product methanol (Figure 8(a)) it can be observed that the benefit of introducing new process alternatives increases as the sales price of methanol increases, while the opposite trend is observed for increasing cost of natural gas. This can be explained as follows: as the sale price of product methanol rises, the value of additional methanol that can be recovered by the process alternatives increases, and the incremental profitability realised increases; similarly as the cost of natural gas increases, the profitability decreases as seen in Figure 8(b). Closely observing Figure 8 (a) and (b) it can be concluded that 
the influence of the methanol sales price and the natural gas cost on process control alternatives $\mathrm{AA}$ and $\mathrm{AB}$ are similar, and as a result, the NPV gap between them remains unchanged.

This is not the case with net margin on the loss of production during non-routine operations (Figure 8 (c)). In this case, as the net margin increases, the NPV of the process control alternatives AA decreases while the NPV of AB increases slightly. This is because of the following factors, $\mathrm{AB}$ in comparison to current operations results in a lower overall production loss during non-routine operations, and when the net margin (value of production loss) increases, the incremental profit derived by $\mathrm{AB}$ over current operations during non-routine operations increases. Therefore, the NPV of the process control alternative AB increases, and vice versa for case AA. As a result, if the net margin increase on loss of production increases, there is an ever increasing economic incentive to choose the process alternative $\mathrm{AB}$ over $\mathrm{AA}$ (i.e. to implement an additional backup control structure). Finally, from analysing Figure 8 (d), it can be observed that a lower cash discount rate provides a better economic incentive to implement both suggested process control alternatives.

In order to understand the influence the variability of the key operation variables would have on the calculated NPV, the influence of increased production rate, the number of non-routine initiating events (steam disturbances), the probability of operator failure to control a non-routine event, as well as the estimated loss of production hours during total failure has been plotted against the NPV in Figure 9.

From analysing Figure 9 (a) a clear trend between increased production rate of the process alternatives and the NPV can be observed. The higher the realised increase in production of process alternatives over current operations, the higher the estimated NPV will be. From analysing Figure 9 (b) it can be observed that the control alternative $\mathrm{AB}$ has a more stable 
NPV/economic performance when confronted with a large variation in the number of initiating events that can occur, while the process alternative AA is more sensitive to changes in the number of initiating events, showing a noticeable reduction in NPV as the number of initiating events increases. This is because of the following factors, process alternative $A B$ has an additional backup control that is dedicated to deal with non-routine process upsets. Thus, even as the number of initiating events increases, the backup control structure ensures minimal overall ILP failure per year (which results in a costly loss of production). In comparison, the process alternative AA only has the operators as an ILP to arrest initiating events. As the number of initiating events increases, the number of ILP failures per year also increases, resulting in a noticeable economic loss that is reflected in the NPV. From analysing Figure 9 (c) a similar observation can be made about the influence of probability of operator failing to intervene on the NPV, as AB having a backup controller has a more stable NPV over the range of probabilities explored. This is because in $\mathrm{AB}$ even if the operator fails to intervene, the backup control ensures minimal overall ILP failure leading to a costly loss of production. In comparison, process alternative AA, which is solely reliant on the operator to intervene, is significantly influenced. As a result, the NPV of AA decreases as the probability of operator failure increases. 

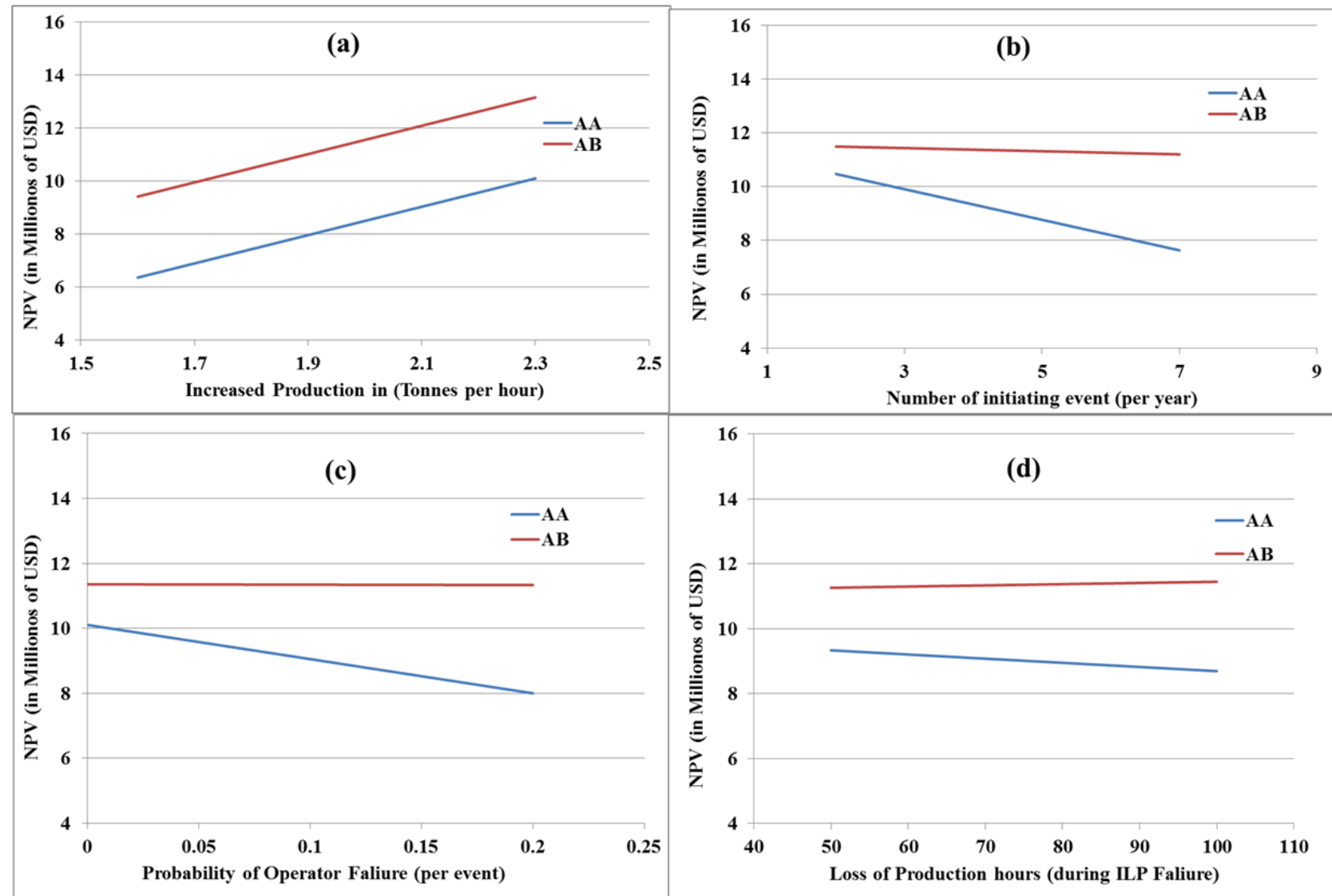

Figure 9 Influence of operational variables (a) increased production rate, (b) number of initiating events (c) probability of operator failure and (d) loss of production hours on incremental NPV.

From the analysis of Figure 9 (d) a similar overall trend can be observed of the influence of the number of lost production hours during a failure on the NPV. In this instance, as the loss of production hours increases, every overall ILP failure has a higher economic cost associated with it. $\mathrm{AB}$ in comparison to the current operations has a marginally lower overall ILP failure per year, despite potentially facing a higher number of initiating events. As the cost of each ILP failure increases due to increasing loss production hours, the NPV of AB is increasing slightly. 
In comparison, the NPV of AA is reduced notably as the loss of production hours increases. This is because, in comparison to the current operations, AA has a much higher probability of overall ILP failure. NOTE: In both Figures 8 and 9 the current operations has an NPV of for zero and sets the base case on which NPV values for AA and AB are derived

Based on the above economic and operational sensitivity analysis, the following key conclusions can be drawn:

- The NPV of both the proposed control alternatives AA and AB remained overwhelmingly positive through all economic and operational variations tested for. This is a further confirmation of the economic attractiveness of the two process control alternatives suggested over current operations.

- In all situations examined, the process alternative AB had a noticeably higher NPV than AA.

- When studying the operational variations it can be seen that process alternative $\mathrm{AB}$ with $\mathrm{a}$ dedicated backup controller has a more stable economic performance. In a scenario where there is uncertainty in operational inputs, it is recommended to implement process alternative $\mathrm{AB}$ over $\mathrm{AA}$. It is important to note that this observation remains consistent even if the PFD of the backup control structure is increased significantly. For example, a PFD assumption of 0.1 (as opposed to the 0.01 PFD used) for the backup control structure will only change the annual profit by USD 40,000 for the base case scenario, which is insignificant in the overall economic picture.

Overall this analysis illustrates the ease in which the proposed methodological approach can be employed to generate practical and relevant information. As such, it can be concluded that the 
proposed methodology is able to systematically and methodically analyse the overall economic impact that a control structure would have on plant wide performance.

\section{CONCLUSIONS}

In this work a novel control structure assessment method was developed to comprehensively calculate the expected economic benefits that a process control structure can bring to unit operations. The approach addressed the gap between existing control performance analysis methodologies and the industrial needs to perform detailed techno-economic analysis. The proposed methodological approach employs NPV analysis and concepts of LOPA analysis to translate techno-economic information into a single NPV value that can be used for an informed decision making process. The methodological approach implicitly takes into account the variability and risk associated with implementing new process control alternatives which neither NPV analysis alone nor simple cost benefit analysis do consider. The application of the proposed methodology to a case study of an industrial methanol distillation column illustrated its ease of application and the clear results that enabled the rating of two process control alternatives against the current operations. As such, it can be concluded that the proposed methodological approach is able to systematically and methodically analyse the overall economic impact a control structure would have on plant wide performance.

\section{ACKNOWLEDGMENTS}

The Authors would like to acknowledge the Carlsberg Foundation Denmark (CF17-0403) for financial support and the technical support provided by the Industrial Information and Control Centre $\left(I^{2} C^{2}\right)$, New Zealand. 


\section{REFERENCES}

(1) Williams, T. J. Economics and the Future of Process Control. Automatica 1965, 3 (1), 113.

(2) Jelali, M. An Overview of Control Performance Assessment Technology and Industrial Applications. Control Eng. Pract. 2006, 14 (5), 441-466.

(3) Harris, T. J.; Yu, W. Controller Assessment for a Class of Non-Linear Systems. J. Process Control 2007, 17 (7), 607-619.

(4) Yu, W.; Wilson, D. I.; Young, B. R. Control Performance Assessment for Nonlinear Systems. J. Process Control 2010, 20 (10), 1235-1242.

(5) Mears, L.; Stocks, S. M.; Sin, G.; Gernaey, K. V. A Review of Control Strategies for Manipulating the Feed Rate in Fed-Batch Fermentation Processes. J. Biotechnol. 2017, $245,34-46$.

(6) Craig, I. K.; Henning, R. G. D. Evaluation of Advanced Industrial Control Projects: A Framework for Determining Economic Benefits. Control Eng. Pract. 2000, 8 (7), 769780.

(7) Marlin, T. E.; Perkins, J. D.; Barton, G. W.; Brisk, M. L. Benefits from Process Control: Results of a Joint Industry-University Study. J. Process Control 1991, 1 (2), 68-83.

(8) Di Mascio, R.; Barton, G. . The Economic Assessment of Process Control Quality Using a Taguchi-Based Method. J. Process Control 2001, 11 (1), 81-88.

(9) Lear, J. B.; Barton, G. W.; Perkins, J. D. Interaction between Process Design and Process Control: The Impact of Disturbances and Uncertainty on Estimates of Achievable 
Economic Performance. J. Process Control 1995, 5 (1), 49-62.

(10) Contreras-Dordelly, J. L.; Marlin, T. E. Control Design for Increased Profit. Comput. Chem. Eng. 2000, 24 (2-7), 267-272.

(11) Bauer, M.; Craig, I. K. Economic Assessment of Advanced Process Control - A Survey and Framework. J. Process Control 2008, 18 (1), 2-18.

(12) Johnson, R. W. Beyond-Compliance Uses of HAZOP/LOPA Studies. J. Loss Prev. Process Ind. 2010, 23 (6), 727-733.

(13) CCPS (Center for Chemical Process Safety). Layer of Protection Analysis: Simplified Process Risk Assessment; Wiley, 2001.

(14) Ramírez-Marengo, C.; de Lira-Flores, J.; López-Molina, A.; Vázquez-Román, R.; Carreto-Vázquez, V.; Mannan, M. S. A Formulation to Optimize the Risk Reduction Process Based on LOPA. J. Loss Prev. Process Ind. 2013, 26 (3), 489-494.

(15) Braccia, L.; Marchetti, P. A.; Luppi, P.; Zumoffen, D. Multivariable Control Structure Design Based on Mixed-Integer Quadratic Programming. Ind. Eng. Chem. Res. 2017, 56 (39), 11228-11244.

(16) Gutierrez, G.; Ricardez-Sandoval, L. A.; Budman, H.; Prada, C. An MPC-Based Control Structure Selection Approach for Simultaneous Process and Control Design. Comput. Chem. Eng. 2014, 70, 11-21.

(17) Zumoffen, D. A.; Braccia, L.; Marchetti, A. G. Economic Plant-Wide Control Design with Backoff Estimations Using Internal Model Control. J. Process Control 2016, 40, 93-105.

(18) Kookos, I. K.; Perkins, J. D. Control Structure Selection Based on Economics: Generalization of the Back-off Methodology. AIChE J. 2016, 62 (9), 3056-3064.

(19) Psaltis, A.; Kookos, I. K.; Kravaris, C. Plant-Wide Control Structure Selection 
Methodology Based on Economics. Comput. Chem. Eng. 2013, 52, 240-248.

(20) CCPS (Center for Chemical Process Safety). Layer of Protection Analysis: Simplified Process Risk Assessment; Wiley, 2001.

(21) Udugama, I. A.; Wolfenstetter, F.; Kirkpatrick, R.; Yu, W.; Young, B. R. A Comparison of a Novel Robust Decentralised Control Strategy and MPC for Industrial High Purity, High Recovery, Multicomponent Distillation. ISA Trans. 2017, 69, 222-233.

(22) A. Udugama, I.; Munir, M. T.; Kirkpatrick, R.; Young, B. R.; Yu, W. Side Draw Control Design for a High Purity Multi-Component Distillation Column. ISA Trans. 2018, 76, $167-177$.

(23) Kraller, M. A.; Udugama, I. A.; Kirkpatrick, R.; Yu, W.; Young, B. R. Side Draw Optimisation of a High-Purity, Multi-Component Distillation Column. Asia-Pacific J. Chem. Eng. 2016, 11 (6), 958-972.

(24) Udugama, I. A.; Mansouri, S. S.; Huusom, J. K.; Taube, M. A.; Maidl, A.; Young, B. Cost Competitive "soft Sensor" for Determining Product Recovery in Industrial Methanol. In 2017 Moratuwa Engineering Research Conference (MERCon); IEEE, 2017; pp 23-28.

(25) Udugama, I.; Wilson, D.; Munir, T.; Yu, W.; Young, B. What Went Wrong and When?: Multivariate Fault Diagnosis of a High Purity Distillation Column. In Chemeca 2014: Processing excellence; Powering our future; Engineers Australia: Perth, 2014; pp 939947.

(26) Kroiss, D.; Udugama, I. A.; Yu, W. Feasibility of Divided Wall Column for High Purity and High Recovery Methanol Separation. In Modelling, Simulation and Identification / 854: Intelligent Systems and Control; ACTAPRESS: Calgary,AB,Canada, 2017.

(27) Udugama, I. A.; Zander, C.; Mansouri, S. S.; Kirkpatrick, R.; Yu, W.; Young, B. R. A 
Novel Back-up Control Structure to Manage Non-Routine Steam Upsets in Industrial Methanol Distillation Columns. In Computer Aided Chemical Engineering; 2017; pp 1597-1602.

(28) Schmidt, M. S. Villains, Victims, and Heroes: Accounting for the Roles Human Activity Plays in LOPA Scenarios. J. Loss Prev. Process Ind. 2014, 30, 256-262. 